D.O.I: $10.3895 / \mathrm{S} 1808-04482013000300012$

\title{
REDES DE INDÚSTRIAS DE AUTOPEÇAS: ASPECTOS DAS EXPORTAÇÕES NACIONAIS
}

\section{AUTO PARTS INDUSTRIES NETWORKS: ASPECTS OF NATIONAL EXPORTS}

\author{
Bruno Leonardo Santos Menezes ${ }^{1}$; Luciano Pisanu ${ }^{2}$; Valter de Senna ${ }^{3}$; Renelson Ribeiro Sampaio ${ }^{4}$; \\ Márcio Nakayama Miura ${ }^{5}$ \\ ${ }^{1}$ Faculdade de Tecnologia do SENAI - CIMATEC \\ brunomubarak@gmail.com \\ ${ }^{2}$ Faculdade de Tecnologia do SENAI - CIMATEC \\ lpisanu@ fieb.org.br \\ ${ }^{3}$ Faculdade de Tecnologia do SENAI - CIMATEC \\ valter.senna@gmail.com \\ ${ }^{4}$ Faculdade de Tecnologia do SENAI - CIMATEC \\ renelson.sampa@gmail.com \\ ${ }^{5}$ Universidade Estadual do Oeste do Paraná - UNIOESTE \\ adm.parana@gmail.com
}

\begin{abstract}
Resumo
Esse artigo tem como objetivo a análise de dados dos destinos das exportações de autopeças nacionais. Um setor estratégico para a economia brasileira, tendo significativa participação nas exportações do país. Esse conjunto de empresas exportadoras forma um arranjo produtivo local que pode ser analisado através de método estatístico e do estudo das redes complexas. Para realizar essa análise, foi utilizada a linguagem de programação Python com algumas de suas bibliotecas. Grupos de países como a Argentina na América do Sul, os Estados Unidos na América do Norte, o México na América Central e os países da União Europeia na Europa obtiveram destaque como destinos das exportações nacionais em milhões de dólares. Ao contrário de Venezuela, Paraguai, África do Sul, Chile e Uruguai que obtiveram um decréscimo dos seus percentis. Os testes indicaram que as redes que compõem os destinos das exportações nacionais seguem uma lei de potência e são redes livre de escala e que para o Brasil ser competitivo $e$ maximizar ganhos com exportações de autopeças deve aumentar a quantidade dos países destinos de seus produtos. Conforme os resultados apresentados serão possíveis elaborar estratégias utilizando o estudo das redes complexas e a lei de Pareto, de acordo com as necessidades de cada um dos canais de distribuição existentes nas redes analisadas.
\end{abstract}

Palavras-chave: sistemas complexos; redes complexas; arranjo produtivo local; setor automotivo; logística.

\section{Introdução}

Este artigo busca contribuir com a literatura a partir de uma perspectiva de estudo das redes complexas e da lei de Pareto. Ao propor e fornecer indícios que de acordo com este panorama, é possível estudar e fazer previsões estratégicas das exportações do setor de autopeças brasileiro. 
Novos estudos podem considerar outros setores e diferentes atividades econômicas com a abordagem proposta. Fusco e Dias (2010) desenvolveram um estudo para entender os relacionamentos e a compreensão dos pressupostos do relacionamento das redes de empresas de autopeças, seus resultados revelam aspectos das condições de equilíbrio existentes no relacionamento entre organizações, indícios sobre melhorias nestas relações e forneceram uma ferramenta gerencial para que as empresas de autopeças possam avaliar as contribuições de suas alianças e parcerias para aumentar a competitividade.

Evidências apresentam um direcionador para a concentração de investimento nas exportações de autopeças brasileiras, um setor importante para o país. Foi realizado levantamento bibliográfico e documental através de método estatístico e do estudo das redes complexas em dados fornecidos pelo MDIC - Ministério do Desenvolvimento, Indústria e Comércio Exterior (2011) dos destinos das exportações em milhões de dólares do setor de autopeças (incluindo pneumáticos) do mercado industrial brasileiro.

As indústrias de autopeças formam um arranjo produtivo estratégico para qualquer região do país que deseja atrair investimentos das grandes montadoras. Segundo García e Méndez (2004), arranjo produtivo é um conjunto de unidades de produção, ligadas através de relações de entrada e saída em um tempo determinado. Essas relações entre unidades produtivas podem ser representadas através de redes complexas, que podem ser entendidas como representações dos sistemas complexos. Nussenzveig (2008) afirma que sistemas complexos são formados por um grande número de unidades simples, porém interligadas entre si, onde uma exerce influência na outra.

É possível observar essa complexidade nas relações comerciais entre países e organizações, interações que podem ser representadas por diversas formas e ligações. Para Newman (2008), as conexões entre os elos de determinado sistema formam uma rede, a estrutura dessa rede deve afetar não só as transações econômicas, bem como outros tipos de interações. Qualquer teoria de interação que ignora essas redes pode ser considerada incompleta, pois não poderá levar em consideração alguns fenômenos importantes e cruciais. Estudar essas redes pode fornecer informações valiosas sobre como determinados sistemas se comportam em relação a condições específicas. Angelis (2005) observa que as redes complexas não apresentam regularidade e padrão, ou seja, os vértices podem apresentar graus diferentes entre si.

Os diversos tipos de redes complexas possuem propriedades características de acordo com sua estrutura. $\mathrm{O}$ estudo das redes possui vários enfoques. Os primeiros estudos partiram das ciências exatas. Para Boccaletti et al (2006) a formalização matemática para representar as redes complexas é a teoria dos grafos de Euler. O grafo é um conjunto de nós, conectados por arestas, que em conjunto, formam uma rede. A teoria dos grafos diz que um grafo $G=(X, Y)$ é uma estrutura matemática de dois conjuntos $\mathrm{X}$ e $\mathrm{Y}$ finitos. Os elementos que compõe o conjunto $\mathrm{X}$ são chamados 
e vértices ou nós. Os elementos de Y são as arestas com um conjunto de um ou dois vértices (GROSS e YELLEN, 2006).

Outra forma de representar essas redes e suas relações é através de dígrafos, segundo Carrington, Scott e Wasserman (2005) um dígrafo é um grafo com direção que pode representar relações de importação e exportação entre nações. É possível estudar as relações de organizações em arranjos produtivos locais através de redes complexas, esses estudos podem definir as características de como esses sistemas complexos podem reagir às imprevisibilidades do mercado.

\section{Desenvolvimento}

\subsection{Mercado e cenário atual}

Desde os anos 90, a indústria brasileira de autopeças sofre transformações internas e setoriais significativas. Internamente ocorreu a redução dos níveis hierárquicos e do quadro de pessoal, nas áreas de produção, engenharia e gestão, uma consequência da terceirização. No setor ocorreu à saída de empresas pequenas, através de fusões e aquisições entre as médias e grandes empresas. Reduzindo assim o número de empresas consideravelmente, com essa nova realidade as empresas foram inseridas em redes logísticas globais (SALERNO, 2002 apud TOLEDO et al, 2008).

As organizações de autopeças buscaram se adaptar de maneira dinâmica exigências do mercado que estão inseridas, criando seu próprio ambiente interno para atender seus consumidores. Robles (2001) concorda que as empresas de autopeças além de concorrerem em escala global, passaram a realizar os processos como sistemistas (fornecedores de sistemas prontos) dentro das montadoras, como exemplo, os processos de submontagens.

A necessidade dos fornecedores de autopeças assumirem funções como sistemistas, revela que uma rede de empresas de autopeças é estratégica para implantação de uma indústria de fabricação de automóveis em determinada região. Essas organizações devem possuir elevado nível de serviço em suas operações e capacidade para integração de informações com as montadoras e outros parceiros. A ANFAVEA - Associação Nacional dos Fabricantes de Veículos Automotores (2011) divulgou em seu anuário da indústria automobilística brasileira, que o faturamento em milhões de dólares das indústrias de autopeças cresceu de 1977 a 2010. O faturamento das organizações foi convertido em dólar pela taxa média de cada ano. Na Figura 1 é possível observar que o faturamento sempre esteve em crescimento, porém de 2003 a 2009 essa tendência aumentou. 
Figura 1 - Faturamento das indústrias de autopeças no Brasil

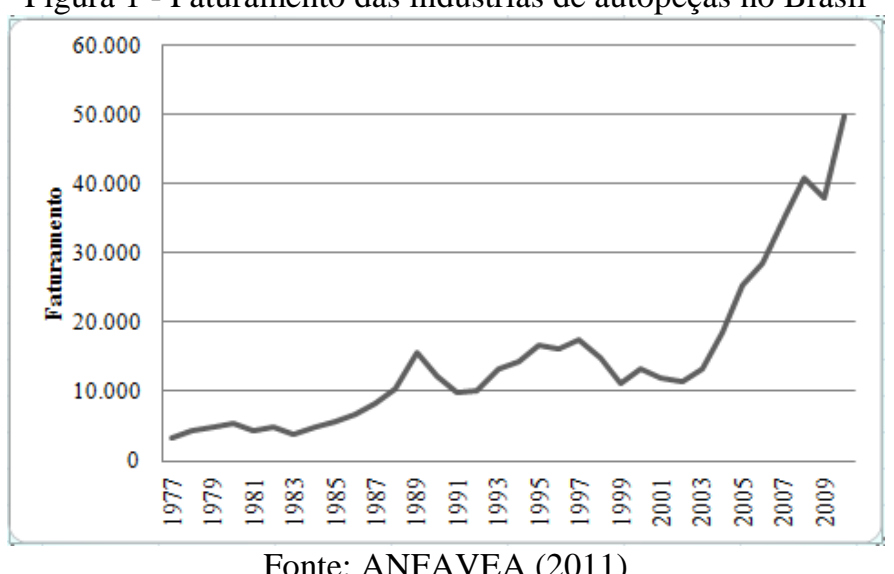

Fonte: ANFAVEA (2011)

A Figura 2 ilustra em formato percentual que a indústria automotiva é a responsável pela maior parte do faturamento das indústrias de autopeças.

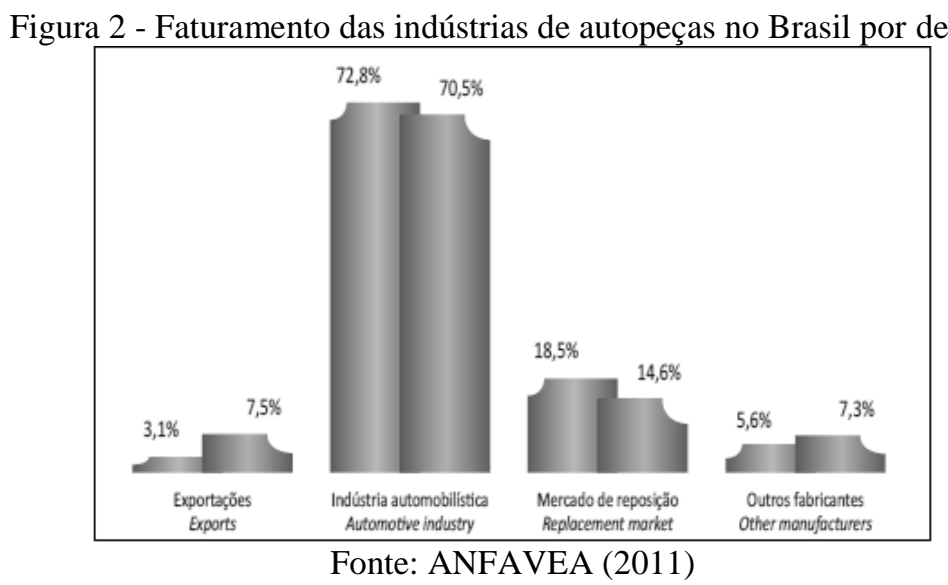

Com a necessidade das indústrias de autopeças prestarem um serviço de qualidade como sistemistas, seu crescente faturamento está ligado ao desempenho das montadoras de automóveis no mercado. Para as organizações que fabricam automóveis é estratégico que para sua instalação em determinada região, que analisem quais locais dispõe de redes empresariais do setor de autopeças, capazes de atender suas necessidades no mercado global.

As últimas informações divulgadas em 2008 pela ABDI - Agência Brasileira de Desenvolvimento Industrial revela que a estrutura de fornecedores do setor automobilístico está subdividida em diferentes níveis. No primeiro estão os fornecedores de sistemas prontos para as montadoras, também denominados de sistemistas, com intensa participação na produção e no desenvolvimento de novos projetos, predominando grandes empresas estrangeiras. Os sistemistas no primeiro nível tem reduzido o número de fornecedores diretos para as montadoras. No segundo nível, estão os fornecedores de partes e peças. Em um terceiro nível estão os fornecedores de matérias-primas para os dois primeiros níveis. 
Atualmente a empresas de autopeças devem fornecer nos dois níveis da rede de empresas do setor automotivo, aumentando a complexidade de suas operações em nível internacional. Para Weiss (1997), os fornecedores estrangeiros geralmente não são substituídos por completo, porém um dos benefícios da existência de fornecedores nacionais é o contínuo processo de inovação e de aperfeiçoamento de produtos e processos na cadeia produtiva. A utilização de fornecedores de autopeças locais pode trazer benefícios ligados a inovações em toda rede das montadoras, além da adoção de melhorias em seus processos e novas tecnologias. A manutenção das organizações de autopeças no Brasil é fundamental para a sobrevivência do setor automotivo nacional.

\subsection{Decisão de localização e canais das exportações}

Weiss (1997) observa que as condições de preço, qualidade e serviços oferecidos são critérios complementares de seleção dos fornecedores de montadoras em determinada região. Para o autor, as relações cooperativas e contratos de longo prazo favorecem o deslocamento de fornecedores para as proximidades da fábrica.

Murray, Dowel e Mayes (1999) identificaram fatores na localização de fornecedores do setor automotivo:

a) Acesso ao mercado para seus produtos;

b) Proximidade de mercado para o produto final;

c) $\mathrm{O}$ acesso aos serviços de marketing e publicidade;

d) Acesso a serviços financeiros, contabilidade e serviços legais;

e) $\mathrm{O}$ acesso a serviços de engenharia e pesquisa e desenvolvimento;

f) $\mathrm{O}$ acesso às matérias primas;

g) Oferta disponível de trabalhadores;

h) Nível de habilidade da força de trabalho disponível;

i) Produtividade do trabalhador;

j) Qualidade / adequação do treinamento da força de trabalho e desenvolvimento;

k) Os níveis salariais em comparação com outros potenciais locais;

1) Outros custos trabalhistas em relação a outros potenciais locais;

m) Trabalho / gestão de relações;

n) Custo da terra;

o) Disponibilidade de terras;

p) Disponibilidade de capital financeiro no estado;

q) Impostos estaduais sobre as empresas;

r) Os impostos locais sobre as empresas;

s) Zoneamento e regulamentos de construção; 
t) Regulamentos e exigências ambientais;

u) Qualidade de rodovias interestaduais;

v) Qualidade de rodovias estaduais;

w) Qualidade de estradas vicinais e estradas;

x) Disponibilidade do serviço ferroviário de qualidade;

y) Disponibilidade de serviços de transporte aéreo;

z) Qualidade de serviço de energia elétrica;

aa) O acesso ao combustível;

bb) Preço do combustível;

cc) Fornecimento de água disponível;

dd)Adequação de eliminação de resíduos;

ee) Disponibilidade de serviços de telecomunicações de alta velocidade;

ff) Clima de negócios em geral no estado;

gg) Qualidade de vida;

hh)Disponibilidade de habitação a preços acessíveis;

ii) Qualidade das escolas públicas;

jj) Qualidade das escolas privadas;

kk) Baixa taxa de criminalidade;

11) Ensino superior e pesquisa instalações;

$\mathrm{mm}$ )Comunidade local;

nn)Cooperação dos governos locais;

oo) Cooperação de autoridades estaduais;

pp) Direito para o trabalho e leis.

Os aspectos adaptados da abordagem de Murray, Dowel e Mayes (1999) são complexos, pois envolvem aspectos subjetivos de cada região. A localização de unidades do setor automotivo envolvem diversos fatores, característicos de cada localização, que devem ser levados em consideração para decisões de acordo com as necessidades das empresas.

Para Torres (2001) as unidades produtivas das montadoras e fornecedores de autopeças estão disseminadas em países como Brasil, China e Índia em função do crescimento e acedência da concorrência nos mercados considerados desenvolvidos, e potencial de aumento destas regiões. Os estudos de Lima et al (2002) e Najberg e Puga (2003), concordam que o Estado da Bahia foi escolhido para implantação da atual montadora de veículos na região, devido principalmente aos benefícios fiscais, financeiros e a possibilidade do Governo do Estado realizar obras complementares de infraestrutura. Sfredo et al (2006) afirmam que os principais fatores que as organizações industriais levam em consideração na localização de seus parques industriais são 
fornecedores, comunidade, mercado consumidor, infraestrutura logística e seus concorrentes. Para os autores as montadoras levam em consideração a localização de seus fornecedores de autopeças:

a) O custo de transporte pode justificar a adoção ou não de empresas locais;

b) Qualidade e capacidade financeiras dessas organizações;

c) Aspectos culturais da comunidade também são levados em consideração, pois essas questões influenciam diretamente na contratação dos colaboradores das montadoras;

d) A infraestrutura logística é outro fator decisivo na decisão sobra à localização de uma montadora ou não em determinada região, pois através dos canais de distribuição que todos os produtos são escoados até o mercado consumidor;

e) A localização dos concorrentes e do mercado consumidor é também levada em consideração na decisão sobre a implantação.

Vanalle e Sales (2011) ressaltam que os estudos de Costa e Queiroz (2000), Humphrey e Salerno (2000) deixam claro que a competição sobre as montadoras e necessidade de reduzir gastos e desenvolver novos produtos fez com que as montadoras buscassem fornecedores de autopeças de menor custo global em qualquer região, além de levarem em consideração a capacidade dos fornecedores no desenvolvimento de seus produtos e de fornecer sistemas e subsistemas.

As relações de exportação são realizadas através de um canal de distribuição, para Rosembloom (2011) esses canais são uma coalizão de organizações com o objetivo de realizar trocas comerciais de produtos.

É possível analisar essas relações comerciais pelo método estatístico e do estudo das redes complexas, com objetivo de descrever algumas características desses sistemas complexos de transações e prever como esses processos podem reagir a variáveis externas e internas do mercado as organizações estiverem inseridas.

\section{Procedimentos metodológicos de análise dos dados}

O programa de computador Minitab (versão 15), foi utilizado como ferramenta computacional para análise e construção de informações. Foram utilizados para realização dos experimentos e construção das redes em ambiente computacional:

a) Linguagem de programação Python (versão 2.1.2) com os módulos ipython, networkx e matplotlib;

b) GCC (Coleção de Compiladores GNU), versão 4.6.1, Linux 2;

c) Sistema operacional Linux Ubuntu, versão 11.10;

d) Computador convencional com Processador Intel Atom com (CPU) unidade central de processamento N455 de 1.66 Giga Hertz com 2 núcleos e 32 Bits;

e) RAM (Memória de acesso aleatório) de 2 (GB) Giga Bytes e disco rígido de 30.7 GB. 
De acordo com interpretações dos dados retirados do site oficial do MDIC em 2012, o setor automotivo teve significativa participação nas exportações nacionais nos anos de 2004 a 2010 (Figura 3).

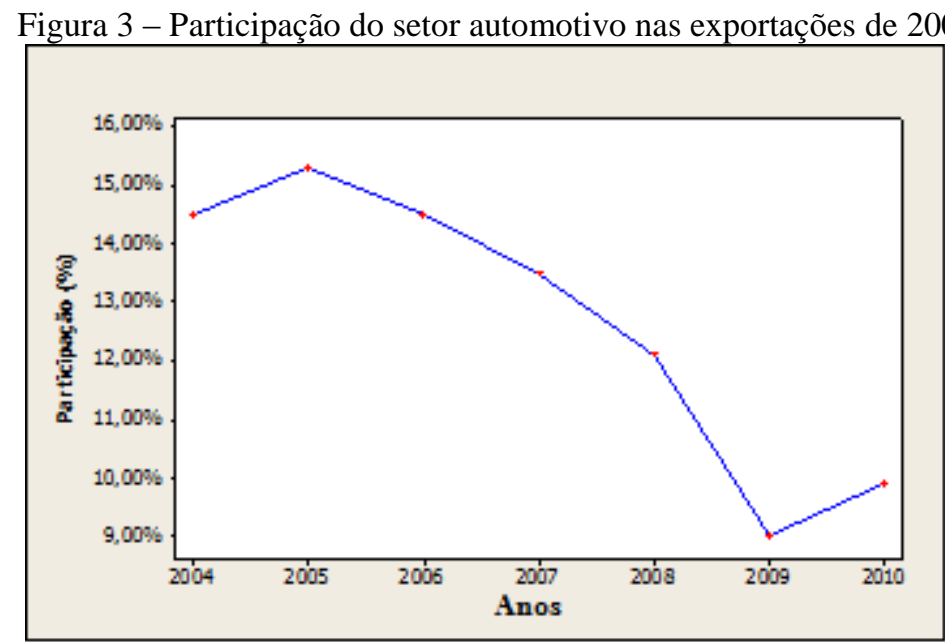

Fonte: Autores (2012)

As exportações do setor automotivo de 2004 a 2010 mantiveram aproximadamente média e mediana respectivamente em $12.686 \%$ e $13.500 \%$, com desvio padrão próximo dos $2.442 \%$, os quartis indicam que existe assimetria à esquerda e erro médio de $0.923 \%$ conforme a Figura 4.

Figura 4 - Análise da participação do setor automotivo nas exportações de 2004 a 2010

\begin{tabular}{|c|c|c|c|c|c|c|c|c|}
\hline Variável & $\mathrm{N}$ & $\mathrm{N}^{*}$ & Média & Erro Médio & Desv Padrão & Minimo & Q1 & Mediana \\
\hline Participação (s) & 7 & 0 & 0,12686 & 0,00923 & 0,02442 & 0,09000 & 0,09900 & 0,13500 \\
\hline $\begin{array}{l}\text { Variável } \\
\text { Participação (\$s) }\end{array}$ & & $\begin{array}{r}Q 3 \\
14500\end{array}$ & $\begin{array}{ll}3 & \text { Máximo } \\
0 & 0,15300\end{array}$ & & & & & \\
\hline
\end{tabular}

Fonte: Autores (2012)

Nos sete anos anteriores, as exportações de autopeças mantiveram crescimento e tiveram participação significativa nas exportações do setor automotivo no Brasil, conforme ilustrado na Figuras 5 e 7.

Figura 5 - Exportação do setor de autopeças em milhões de dólares de 2004 a 2010

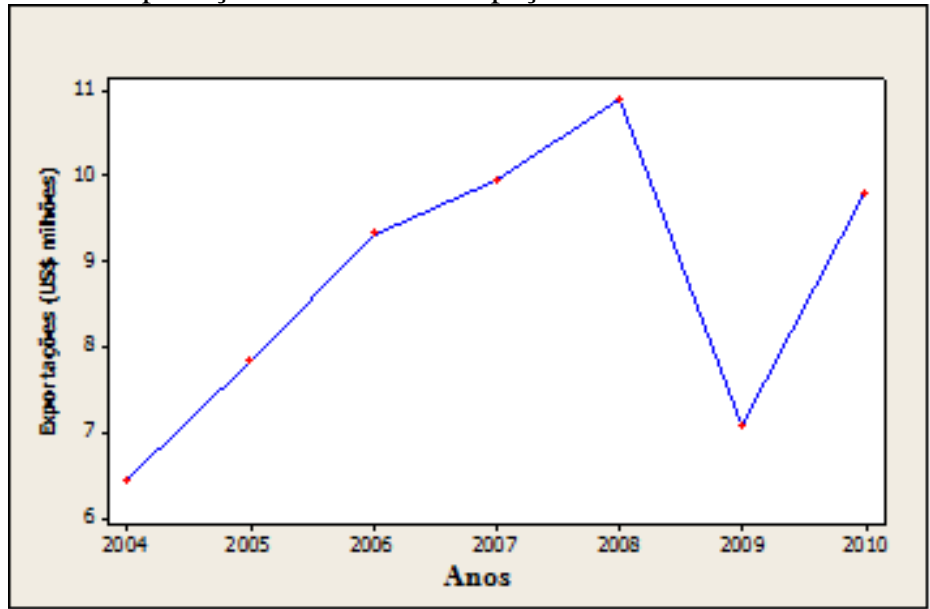

Fonte: Autores (2012) 
As exportações nos anos de 2004 a 2010 tiveram média e mediana de 8.754 e 9.315 milhões de dólares, com desvio padrão próximo dos 1.650, os quartis indicam que existe assimetria à esquerda e erro médio de 0.624 (Figura 6).

Figura 6 - Análise das exportações do setor de autopeças em milhões de dólares de 2004 a 2010

\begin{tabular}{|llrrlclllr|}
\hline Variável & & N & $N^{*}$ & Média & Erro Médio Desv Padrão Minimo & Q1 & Mediana \\
Exportaçöes & (US\$ milhões & 7 & 0 & 8,754 & 0,624 & 1,650 & 6,431 & 7,072 & 9,315 \\
& & & & & & & & & \\
Variável & & & $Q 3$ & Máximo & & & & & \\
Exportações & (US\$ milhões & 9,940 & 10,880 & & & & & \\
\hline
\end{tabular}

Fonte: Autores (2012)

Figura 7 - Participação do setor de autopeças nas exportações do setor automotivo 2004 a 2010

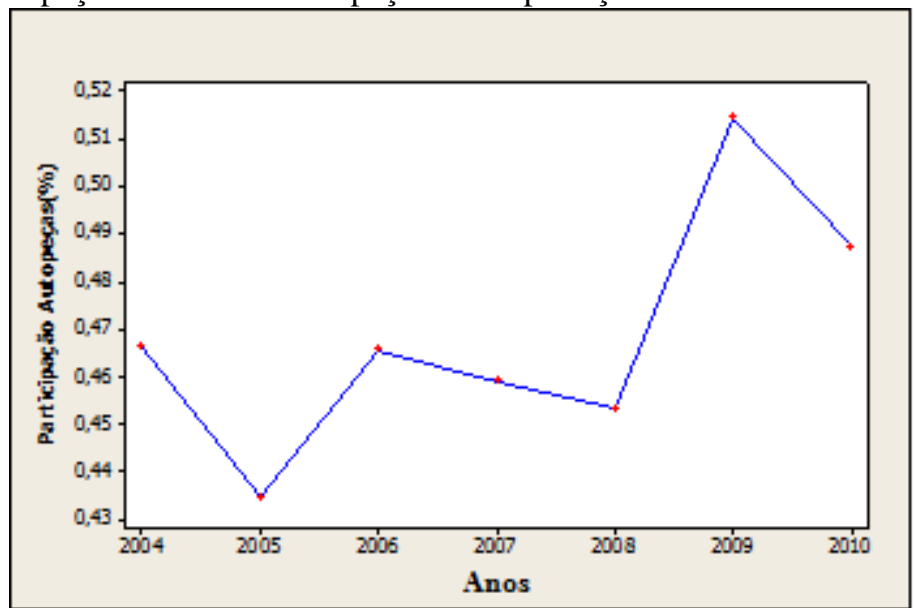

Fonte: Autores (2012)

A participação do setor de autopeças nas exportações do setor automotivo nos setes anos anteriores registrou média e mediana de $46.857 \%$ e $46.560 \%$ com desvio padrão próximo dos $2.562 \%$, os quartis indicam que existe assimetria à direita e erro médio de $0.968 \%$ (Figura 8).

Figura 8 - Análise da participação do setor de autopeças nas exportações do setor automotivo de 2004 a 2010

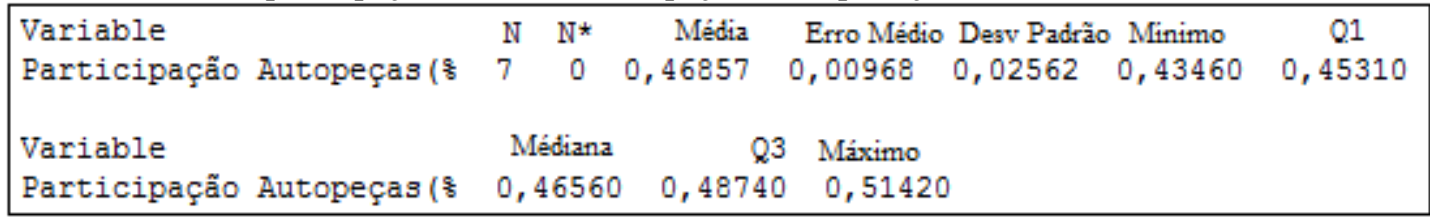

Fonte: Autores (2012)

Com base nos dados do MDIC, o coeficiente de correlação de Pearson das exportações em milhões de dólares das exportações do setor automotivo e autopeças de 2004 a 2010 é quase 0.906. Existindo assim uma correlação forte e positiva entre os valores, conforme ilustrado na Figura 9. 
Figura 9 - Matriz de correlação do setor automotivo em milhões de dólares (exportações Auto US\$ milhões) e autopeças (exportações peças US\$ milhões) de 2004 a 2010

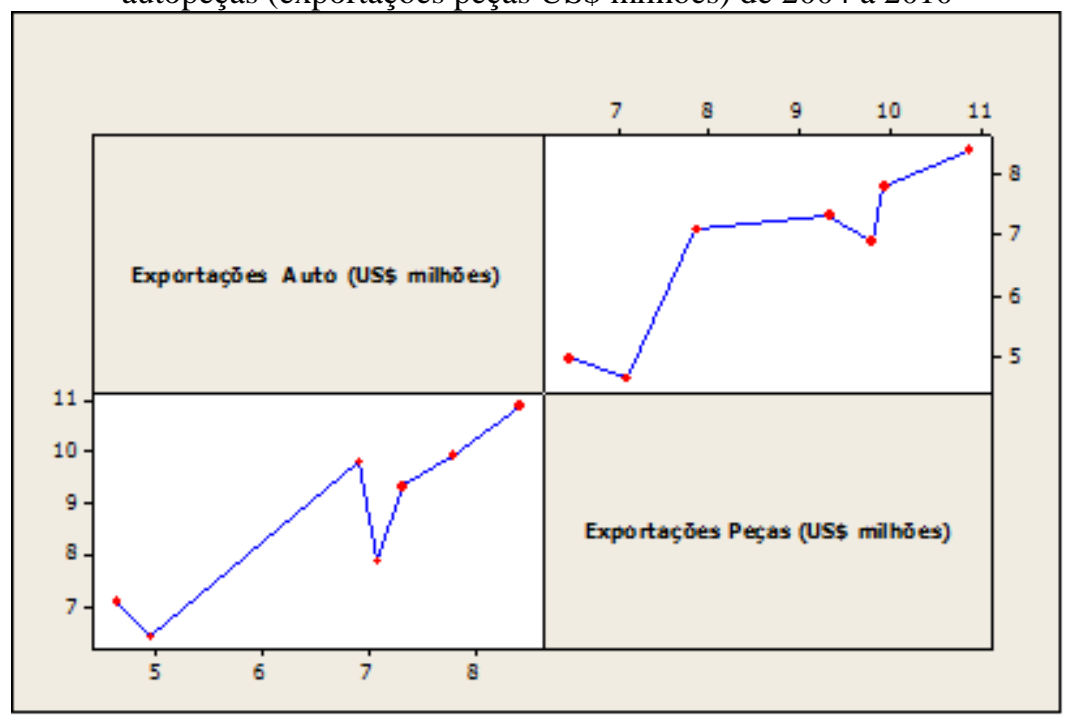

Fonte: Autores (2012)

A Figura 10 ilustra alguns dos principais destinos das exportações de autopeças do Brasil de janeiro a agosto em 2010 e 2011, dados interpretados do MDIC.

Figura 10 - Alguns dos principais países destino das exportações de autoveículos e autopeças de janeiro a agosto em 2010 e 2011

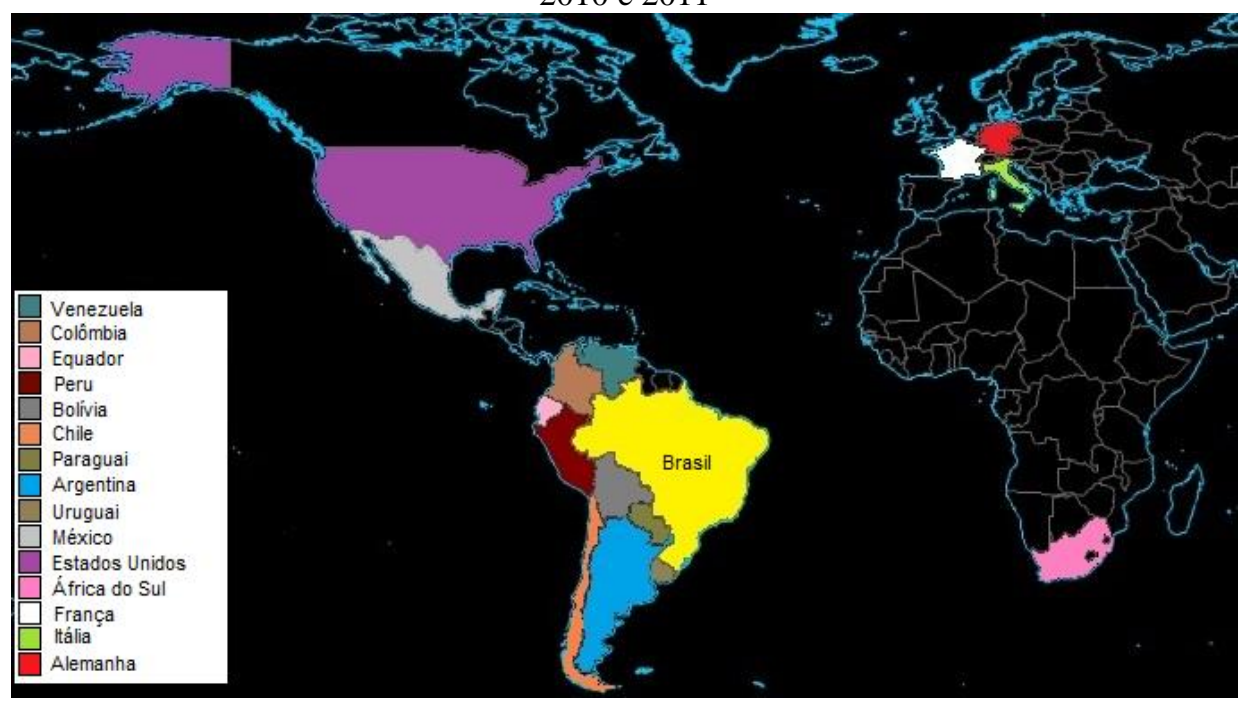

Fonte: MDIC (2011)

De acordo com interpretação de dados do MDIC de janeiro a agosto de 2010 a Argentina, União Europeia, Estados Unidos e México foram os quatro maiores destinos das exportações brasileiras (Figura 11), representando respectivamente quase $36.2487 \%, 17.6070 \% \%, 15.8523 \%$ e $8.9685 \%$. 
Figura 11 - Exportações de autopeças em milhões de dólares de janeiro a agosto em 2010

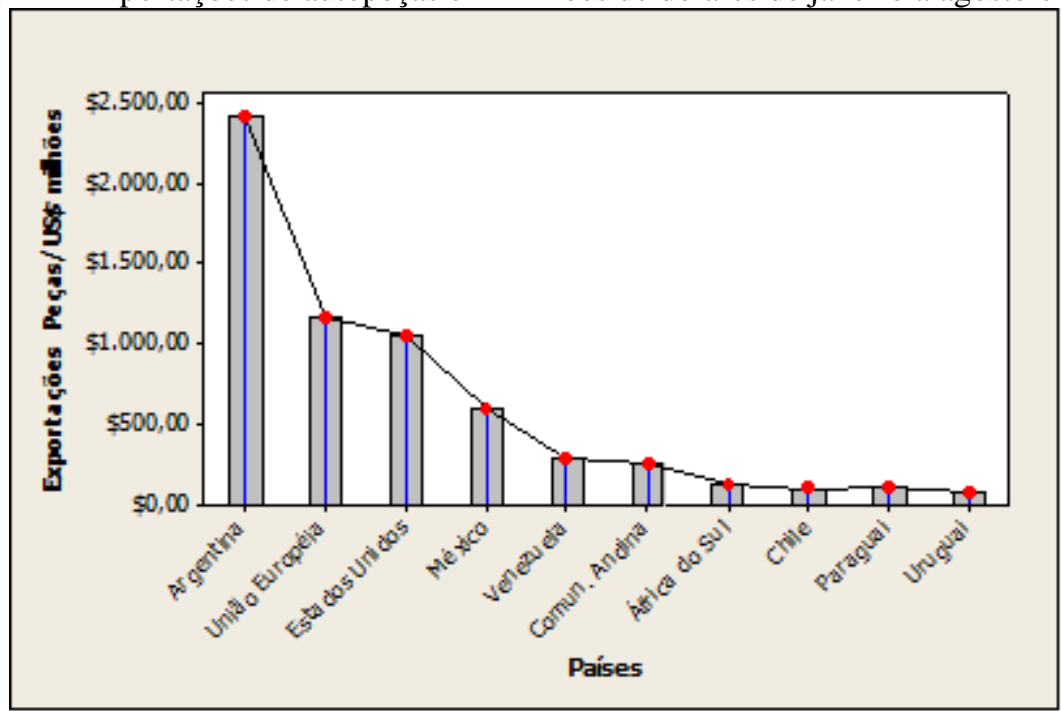

Fonte: Autores (2012)

Na Figura 11, a União Europeia representada por Alemanha com participação de $34.9233 \%$ nas exportações do bloco econômico europeu, França com $9.6252 \%$, Itália com $7.9216 \%$ e Outros Países com 47.5298\%. O MDIC não informa quais dos 27 estados da União Europeia compõem a variável "Outros países". Embora Venezuela e Chile sejam membros da Comunidade Andina os mesmos foram mensurados separadamente pelo MDIC. Atualmente a Comunidade Andina conta com Bolívia, Colômbia, Equador e Peru como países membros e Argentina, Brasil, Chile, Paraguai e Uruguai como membros associados, além de México e Panamá como países observadores.

Dados do MDIC indicam que de janeiro a agosto de 2011 a Argentina, União Europeia, Estados Unidos e México se mantiveram como os quatro maiores destinos das exportações brasileiras (Figura 12), representando respectivamente quase 38.7517\%, 16.6808\%, 15.4982\% e 8.9255\%. A União Europeia representada por Alemanha com participação de $43.0597 \%$, França com $9.1791 \%$, Itália com $8.8806 \%$ e Outros Países com 38.8806\%. O MDIC também não informa em 2011, quais estados compõem a variável "Outros países” e a Comunidade Andina também foi mensurada separadamente de Chile e Venezuela. 
Figura 12 - Exportações de autopeças em milhões de dólares de janeiro a agosto em 2011

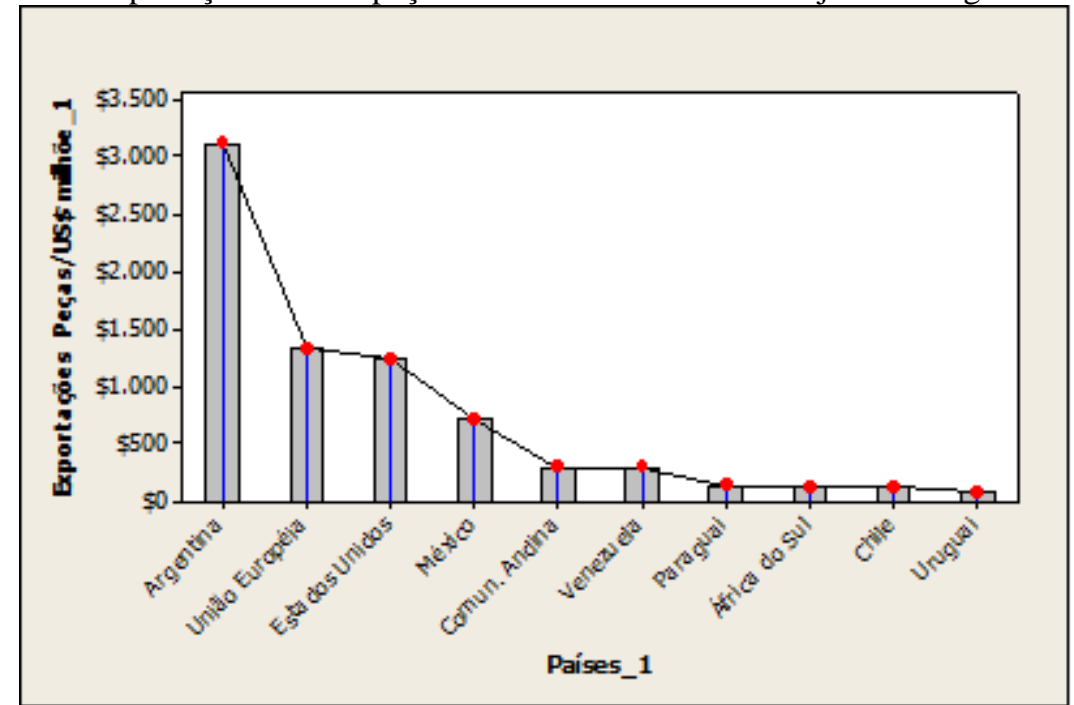

Fonte: Autores (2012)

A Figura 13 indica que comparando os destinos das exportações brasileiras de janeiro a agosto de 2010 e 2011 (Figura 11 e 12), Argentina registrou um aumento de 28,7960\%, União Europeia com 14,1397\%, Estados Unidos com 17,7862\%, México com 19,8997\%, Comunidade Andina com 15,9696\%, Chile com 15,3846\%, Venezuela com 8,5409\%, África do Sul com 4,9180\%, Uruguai com 1,2346\% e Paraguai com 20,0000\%. Argentina liderou esse crescimento, seguida respectivamente por Paraguai, México, Estados Unidos, Comunidade Andina, Chile, União Europeia, Venezuela, África do Sul e Uruguai. A Argentina registrou um crescimento considerável em relação aos outros destinos.

Figura 13 - Aumento (\%) das exportações de autopeças janeiro a agosto em 2010 em relação a janeiro a agosto em

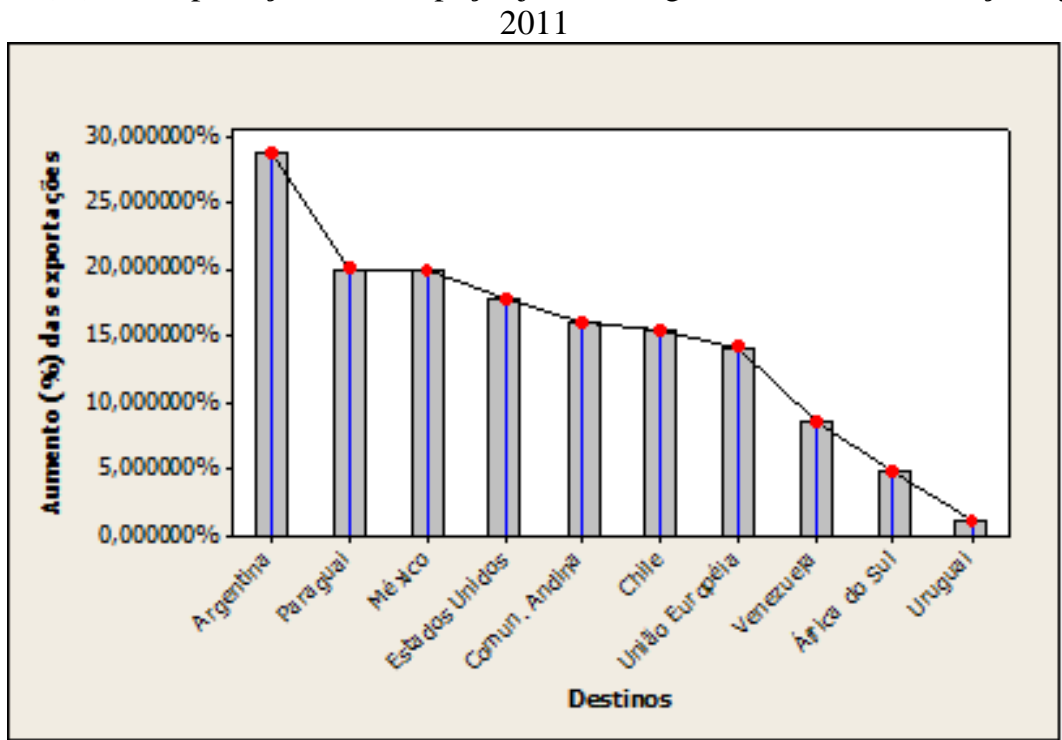

Fonte: Autores (2012) 
Os países destinos das exportações brasileiras podem pertencer a canais de distribuição, caso as entregas das mercadorias a serem exportadas sejam consolidadas para reduzir custos logísticos, conforme ilustrado na Figura 13.

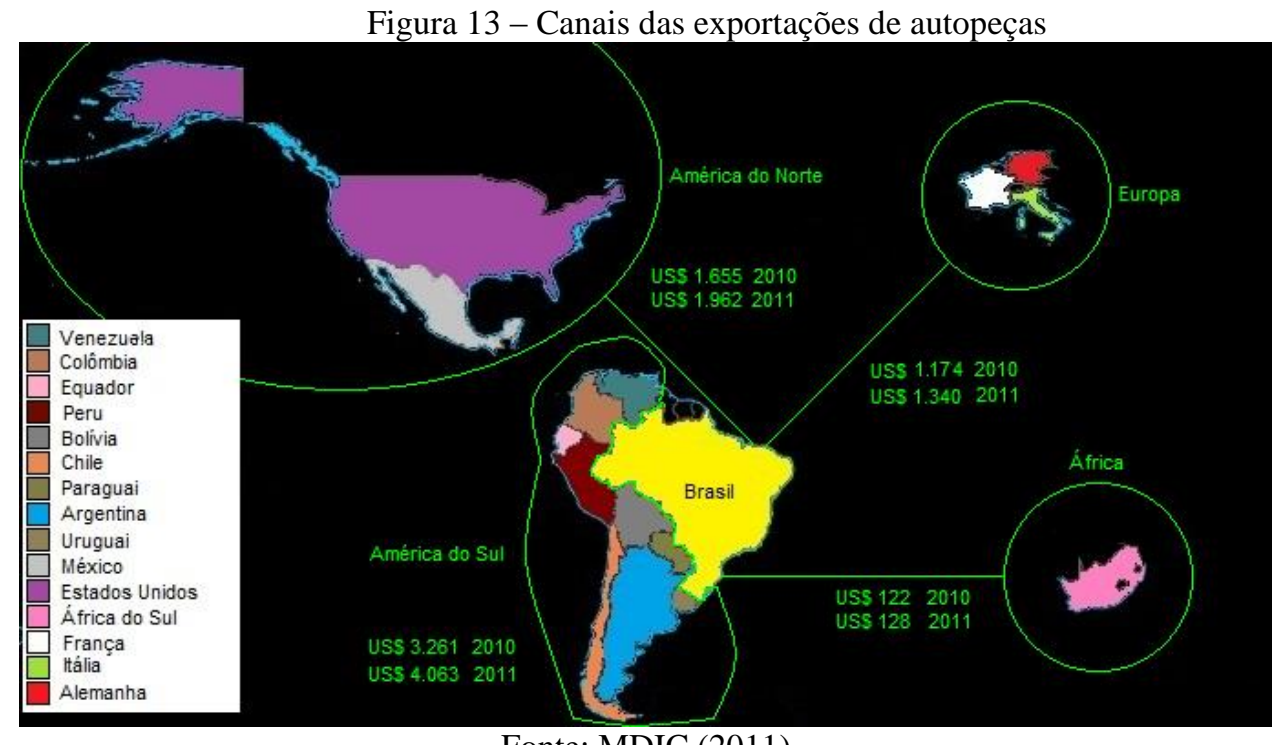

Fonte: MDIC (2011)

Agrupando os países (Figura 13) em quatro grandes canais de distribuição (América do Norte, América do Sul, Europa e África) representou respectivamente 26,6420\%, 52,4952\%, 18,8989\% e 1,9639\% das participações nas exportações nacionais em milhões de dólares de janeiro a agosto de 2010. De janeiro a agosto de 2011 cada canal (América do Norte, América do Sul, Europa e África) quase representou respectivamente 26,1844\%, 54,2239\%, 17,8834\% e 1,7083\% das participações nas exportações nacionais em milhões de dólares.

As Figuras 14 e 15 mostram a contribuição em milhões de dólares de cada um dos possíveis canais analisados nos anos de 2010 e 2011.

Figura 14 - Exportações de autopeças em milhões de dólares por continentes de janeiro a agosto em 2010

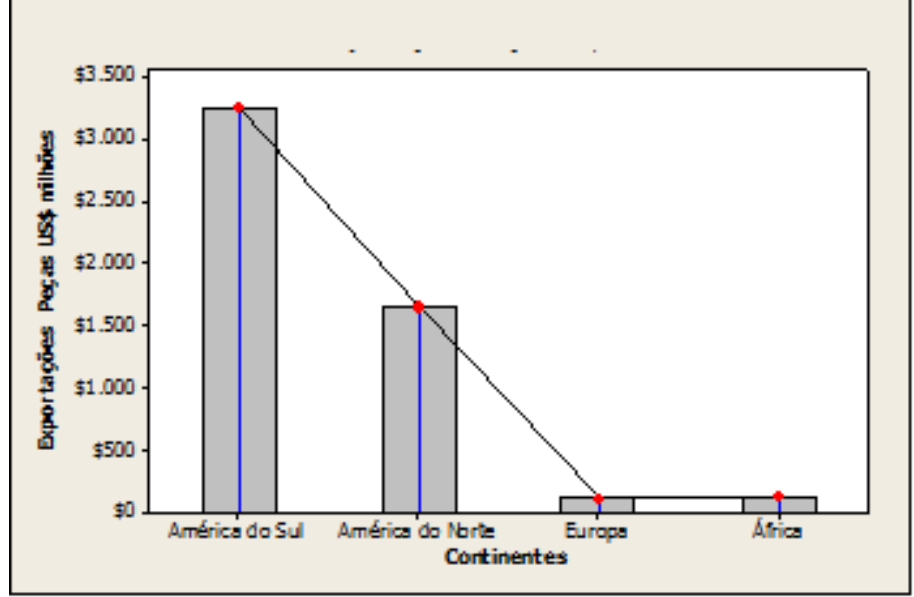

Fonte: Autores (2012) 
Figura 15 - Exportações de autopeças em milhões de dólares por continentes de janeiro a agosto em 2011

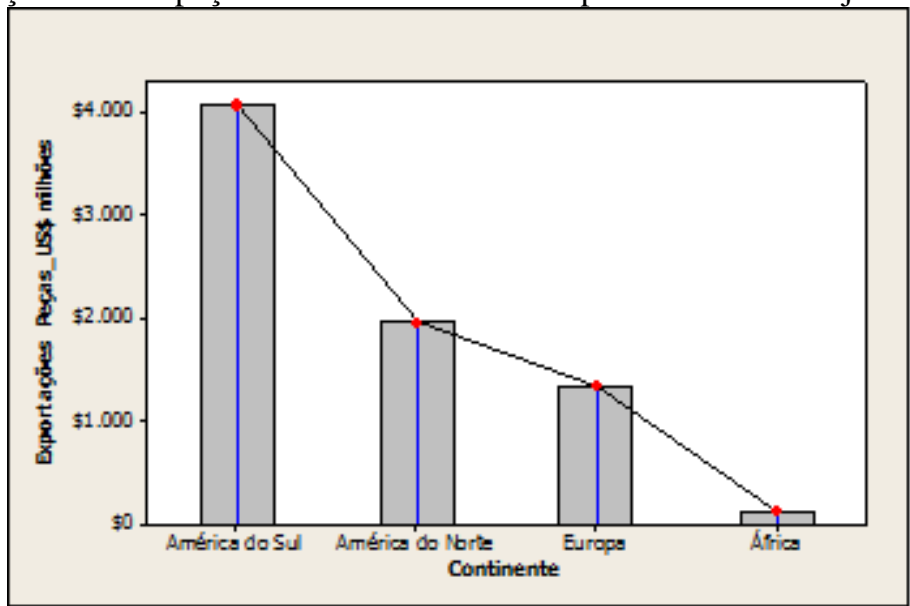

Fonte: Autores (2012)

A América do Sul registrou um aumento de $24,5937 \%$ em comparação aos anos de 2010 e 2011, América do Norte obteve crescimento de 18,5498\%, Europa com 14,1397\% e por fim a África com 4,9180\%. O crescimento da América do Sul tem destaque em relação aos outros possíveis canais.

Figura 16 - Crescimento (\%) das exportações de autopeças por canal de janeiro a agosto em 2010 em relação a janeiro a agosto em 2011

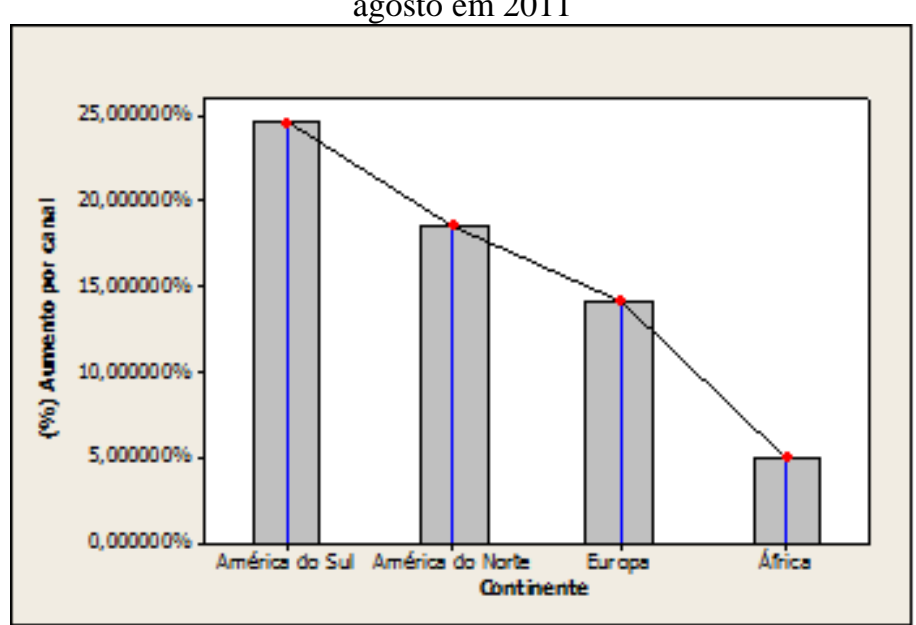

Fonte: Autores (2012)

A Figura 17 representa as redes estrela que foram geradas utilizando a linguagem de programação python com três bibliotecas (ipython, networkx e matplotlib) e os algoritmos disponíveis nos Anexos B e D, com base nos dados ilustrados nas Figuras 11 e 12.

Para gerar as redes foram atribuídos aos nós as siglas dos países destinos das exportações nacionais, as arestas representam os valores exportados em milhões de dólares:

a) Brasil (B para janeiro a agosto de 2010 e B1 para o mesmo período de 2011) como hub (nó que interliga todos os outros nós) da rede;

b) Argentina (A) com aresta igual a 2,417 em 2010 e 3,113 em 2011;

c) Chile (C) com aresta igual a 104 em 2010 e 120 em 2011; 
d) México (M) com aresta igual a 598 em 2010 e 717 em 2011;

e) Uruguai (U) com aresta igual a 81 em 2010 e 82 em 2011;

f) Venezuela (V) com aresta igual a 281 em 2010 e 305 em 2011;

g) União Europeia (UE) com aresta igual a 1,174 em 2010 e 1,340 em 2011;

h) Estados Unidos (EU) com aresta igual a 1,057 em 2010 e 1,245 em 2011;

i) Comunidade Andina (CA) com aresta igual a 263 em 2010 e 305 em 2011;

j) Paraguai (P) com aresta igual a 115 em 2010 e 138 em 2011;

1) África do Sul (AS) com aresta igual a 122 em 2010 e 128 em 2011.

Figura 17 - Redes estrela das exportações de autopeças em milhões de dólares de janeiro a agosto em 2010 e 2011 do mesmo período

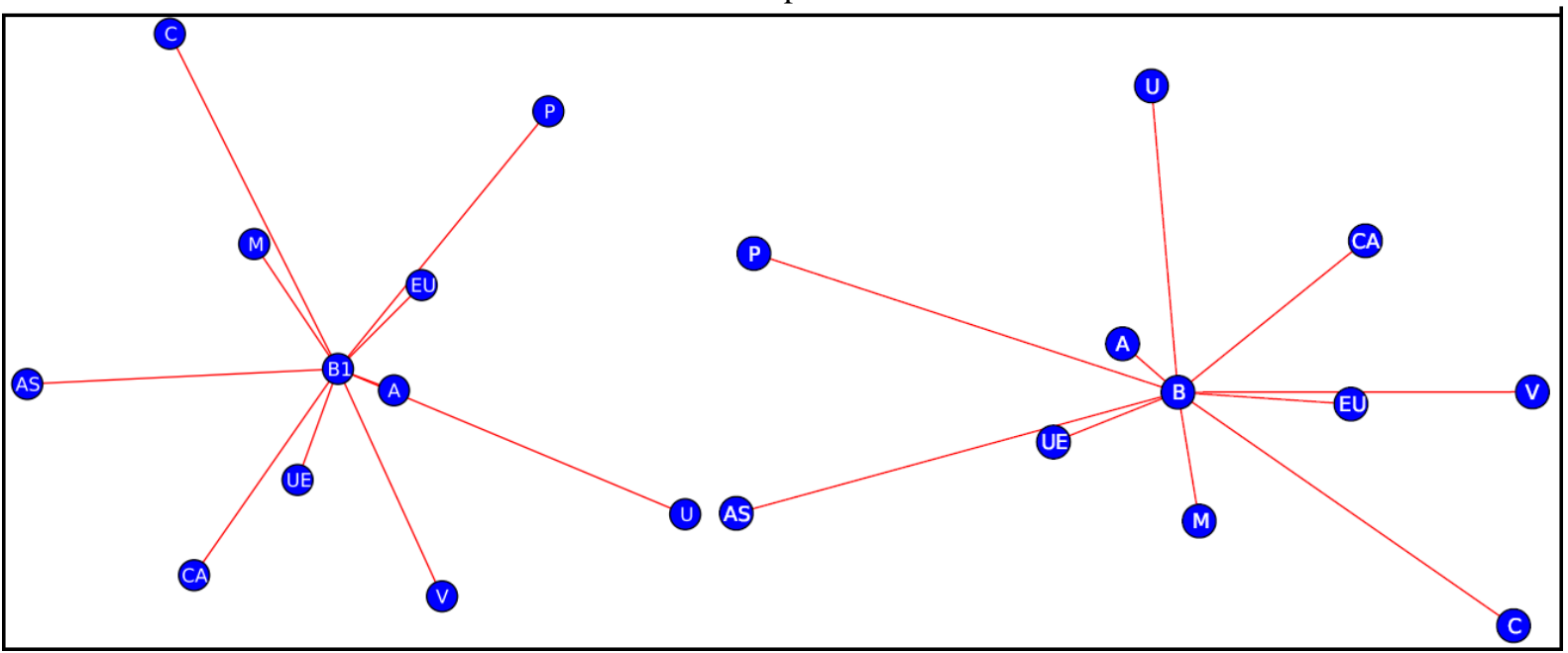

Fonte: Autores (2012)

Na Figura 17 ilustra os nós com maiores valores em suas arestas possuem maior proximidade do hub da rede. Foi obtido o gráfico da distribuição de frequência dos destinos das exportações em milhões de dólares dos anos de 2010 e 2011, conforme as Figuras 16 e 17.

Figura 18 - Gráfico da distribuição de frequência das exportações de autopeças em milhões de dólares de janeiro a agosto em 2010

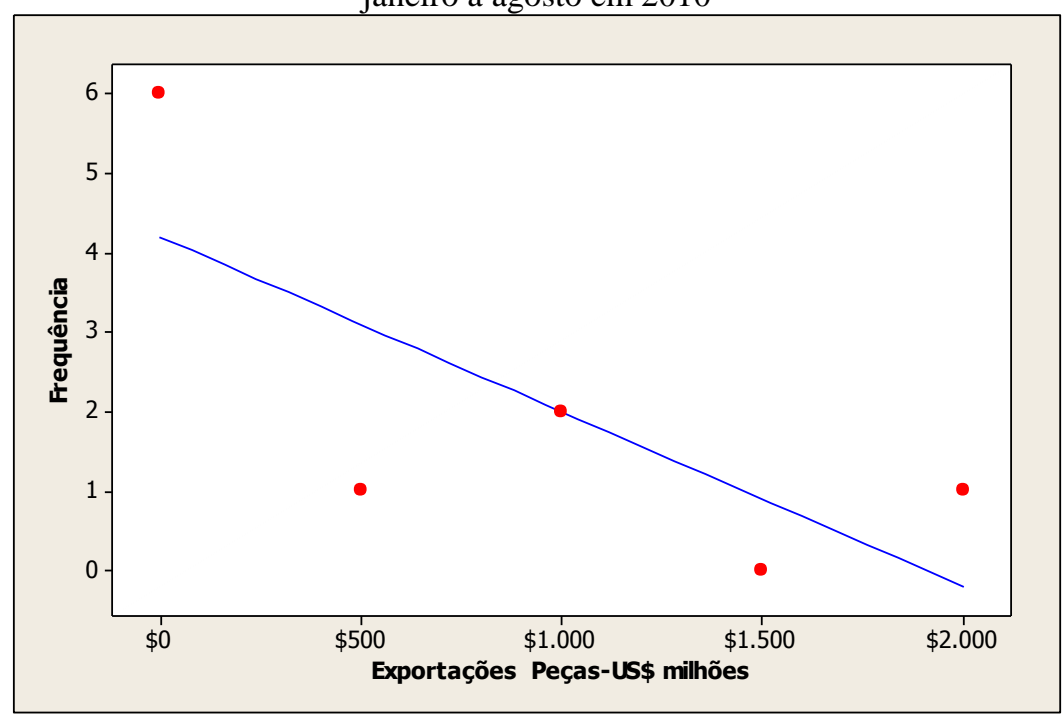

Fonte: Autores (2012) 
Figura 19 - Gráfico da distribuição de frequência das exportações de autopeças em milhões de dólares de janeiro a agosto em 2011

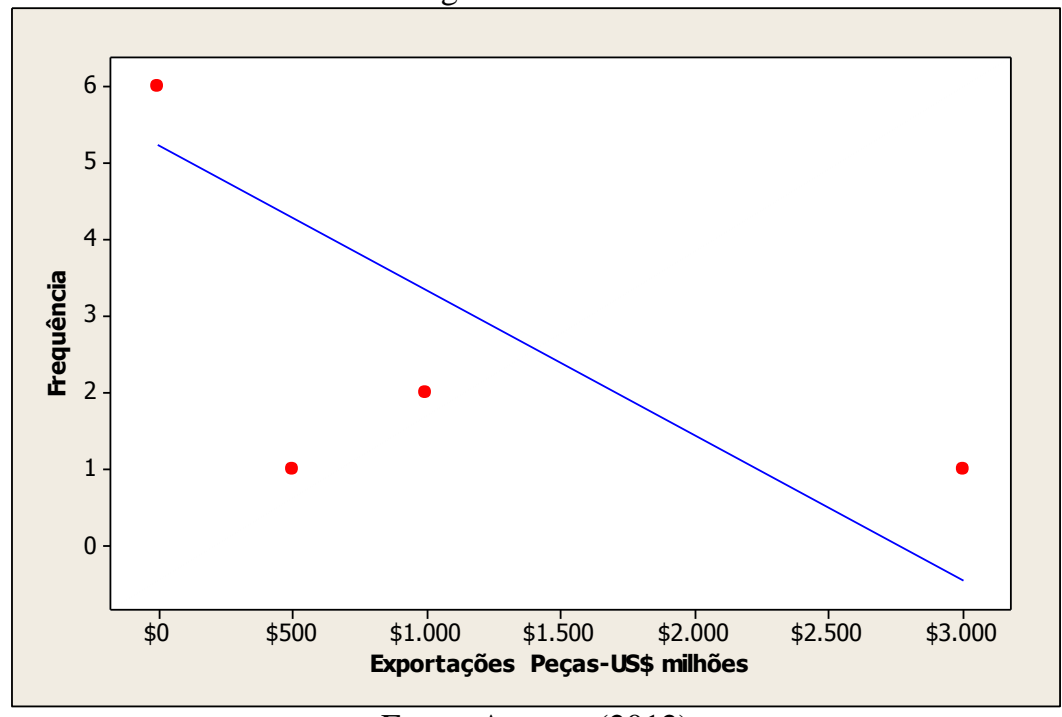

Fonte: Autores (2012)

As Figuras 18 e 19, embora existam uma carência de dados, indicam que as redes geradas (Figura 17) seguem lei de potência, como consequência se trata de redes livre de escala.

Segundo Gleria, Matsushita e Silva (2004) existem sistemas que não possuem comportamento linear e podem ser descritos por lei de potência, que pode ser entendida como uma regra que representa sistemas que apresentam crescimento exponencial.

Pereira; Freitas; Sampaio (2007) acreditam que a propriedade estrutural característica das redes livre de escala é que distribuição da mesma segue uma lei de potência, essas redes são resultado do crescimento ao longo do tempo quando ocorrem escolhas por atores em detrimento de outros. Considerando que as Figuras 18 e 19 indica que a rede estrela (Figura 17) segue uma lei de potência, é possível aplicar a lei de Pareto no conjunto de dados da rede para definir prioridades de atendimento a cada país, conforme Figura 20.

Para Gleria, Matsushita e Silva (2004) a regra de Pareto é uma lei de potência clássica. Segundo Koch (2000) a lei de Pareto de Joseph Moses Juran, baseia-se na descoberta de Vilfredo Pareto em 1897, segundo o mesmo $80 \%$ do trabalho realizado por uma pessoa vêm de $20 \%$ do tempo gasto nesta realização, ou seja, $80 \%$ dos esforços consumidos são irrelevantes. 
Figura 20 - Gráfico de Pareto das exportações de autopeças em milhões de dólares de janeiro a agosto em 2010

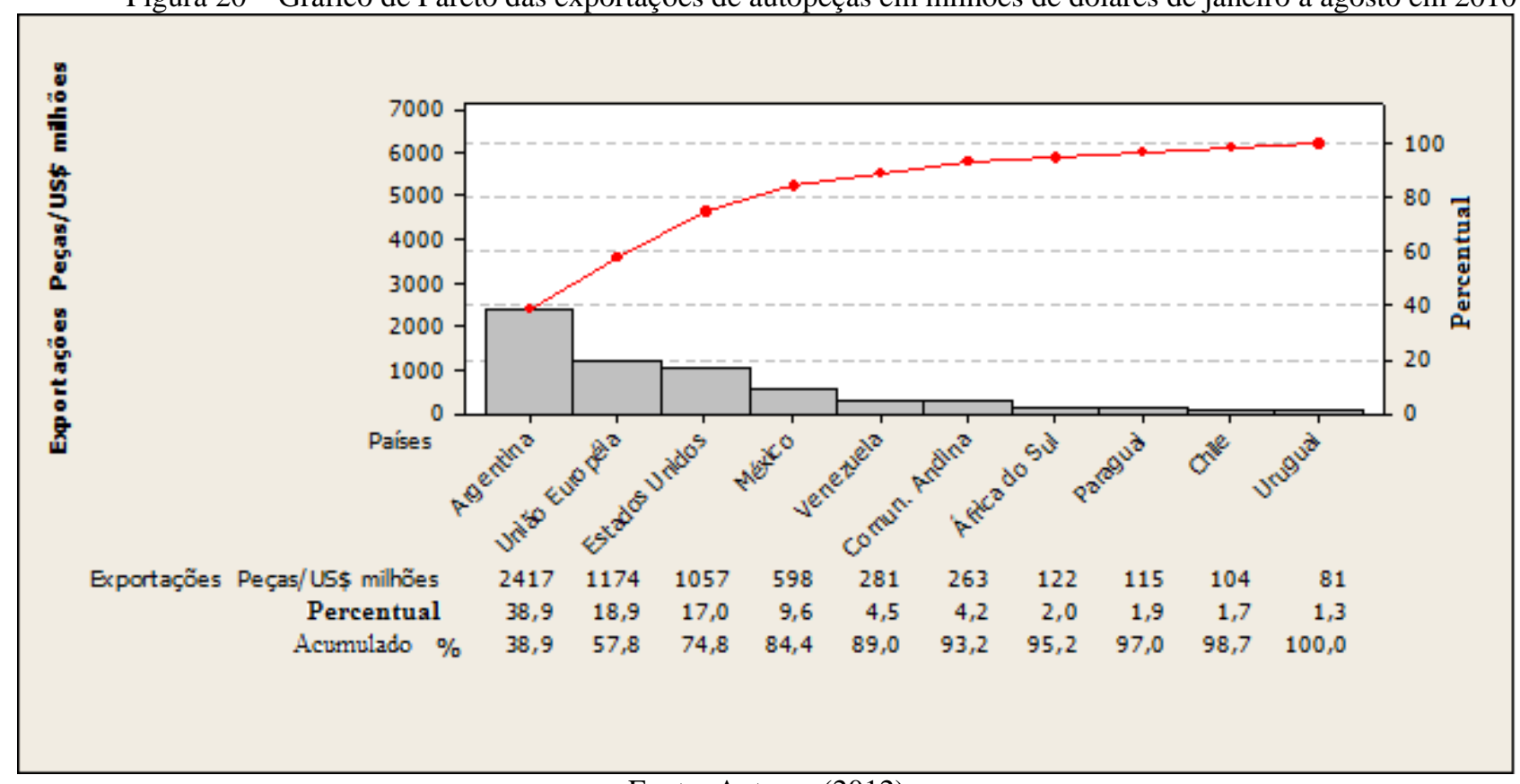

Fonte: Autores (2012)

De acordo com a Figura 20, Argentina, União Europeia, Estados Unidos e México representam aproximadamente $84,4495 \%$ do acumulado dos destinos das exportações nacionais em milhões de dólares, ou seja, 5,246 milhões de dólares de janeiro a agosto de 2010. A soma de todos os outros países equivale a 966 milhões de dólares, quase 15,5505\% do acumulado.

O resultado ilustrado pela Figura 20 também indica que as redes de exportações de autopeças (Figura 17), seguem uma lei de potência e pode ser classificada como uma rede livre de escala. Na Figura 20, os quatro principais países também pertencem a três canais de distribuição: América do Sul, Europa e América do Norte.

Figura 21 - Gráfico de Pareto das exportações de autopeças em milhões de dólares de janeiro a agosto em 2011

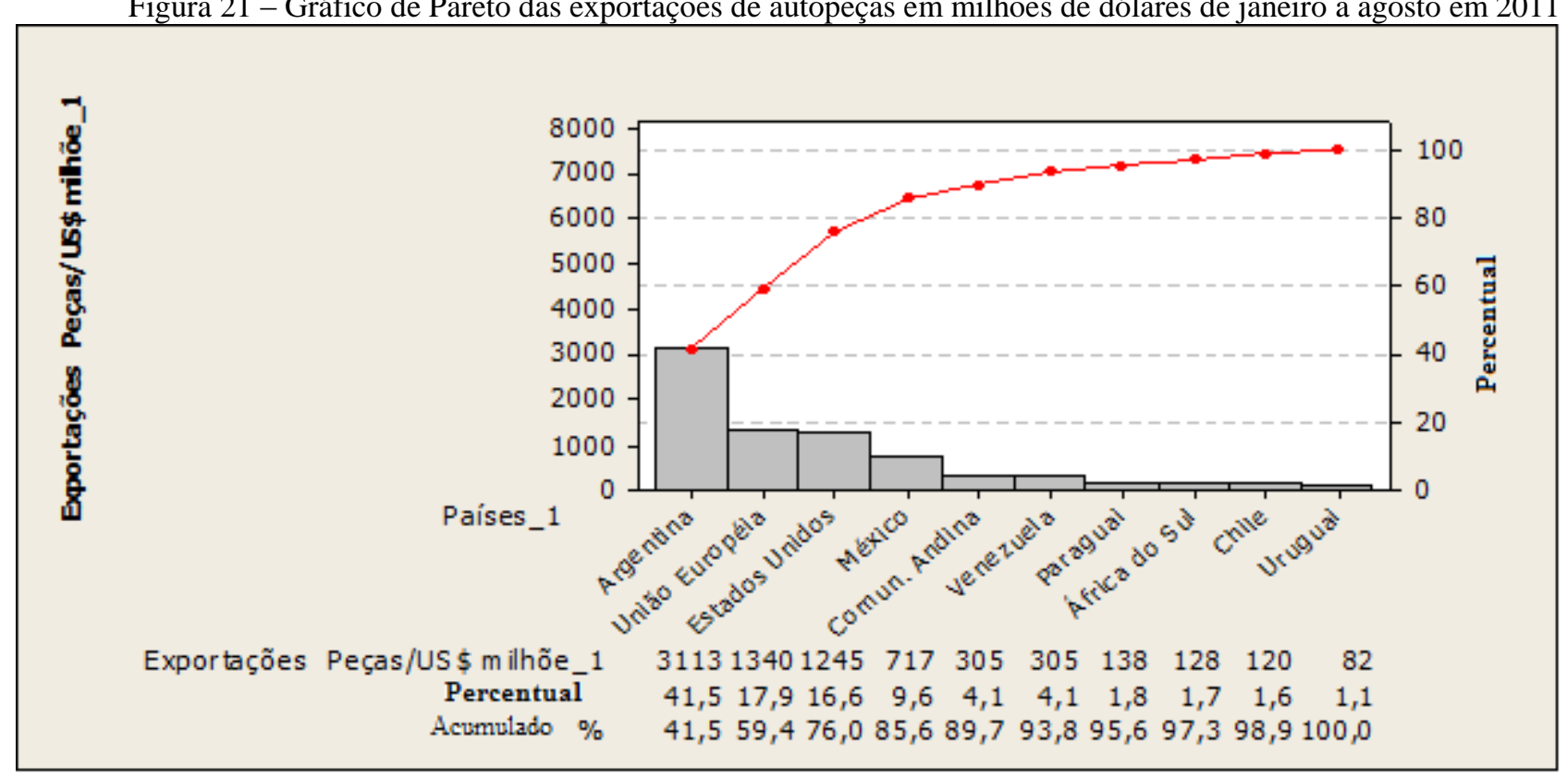

Fonte: Autores (2012) 
Na Figura 21 a Argentina, União Europeia, Estados Unidos e México representam aproximadamente 85,6132\% do acumulado dos destinos das exportações nacionais em milhões de dólares, ou seja, 6,415 milhões de dólares de janeiro a agosto de 2011. A soma de todos os outros países equivale a 1,078 milhões de dólares, quase 14,3868\% do acumulado e confirma que a rede de destinos das exportações nacionais segue lei de potência e que Venezuela, Paraguai, África do Sul, Chile e Uruguai, tiverem um decréscimo em cada percentil de janeiro a agosto de 2011, em relação ao mesmo período em 2010.

É possível gerar uma rede considerando o atendimento dos países destinos das exportações nacionais em milhões de dólares, através das informações geradas pela lei de Pareto (Figura 21) e cada canal de distribuição que o mesmo pertence (Figura 22). Os algoritmos de construção das redes representadas pela Figura 22 estão disponíveis nos Anexos C e E.

Figura 22 - Redes de prioridade das exportações de autopeças em milhões de dólares de janeiro a agosto em 2010 e

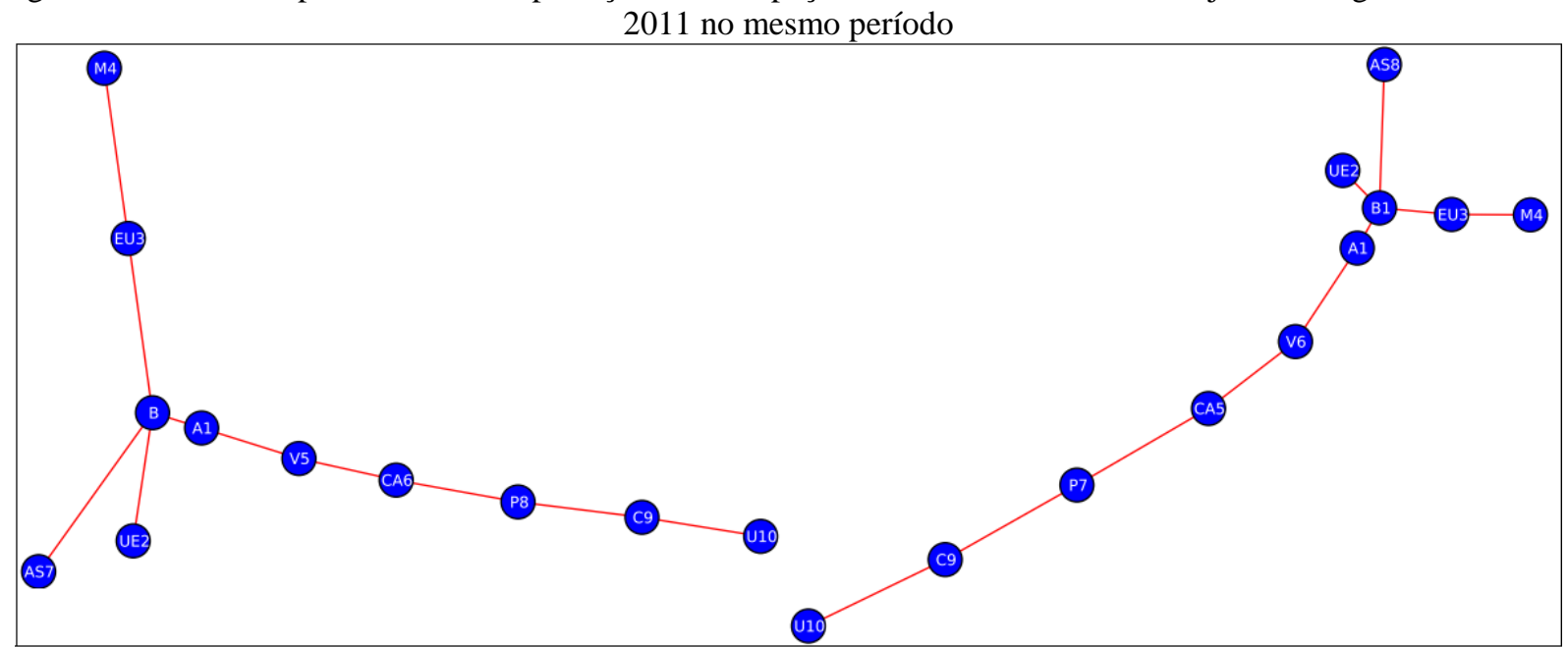

Fonte: Autores (2012)

Na Figura 22, foram atribuídas numerações em ordem crescente a cada nó das redes de 2010 e 2011, de acordo com a ordem de prioridade definida pela lei de Pareto e ilustrada na Figura 21. O Brasil em 2010 e 2011 possui quatro canais de distribuição em potencial, cada canal apresenta países (nós) onde às arestas com maiores valores apresentam maior proximidade em relação ao hub da rede. O canal de distribuição que representa a América do Sul possuiu um número maior de nós a serem atendidos, totalizando seis países e a Comunidade Andina. O continente Europeu, representado pela União Europeia, apresenta um nó que representa mais de quatro países. América do Norte com dois nós e o continente Africano com um país.

Analisando o comportamento das redes, ilustradas pela Figura 22, o nó Argentina se aproximou do hub da rede, ou seja, aumentou o valor de sua aresta e manteve ordem de prioridade um. No canal de distribuição da América do Sul, o nó CA em 2011 ultrapassou P em ordem de prioridade, ou seja, o valor de sua aresta foi superior ao de P. UE manteve ordem de prioridade dois 
e aproximou do hub. EU e M mantiveram os mesmos valores de prioridade e se aproximaram do hub da rede.

Com base nos experimentos realizados nesse estudo, é provável que a rede estrela de exportações de autopeças do Brasil, tenha a topologia parecida com a ilustrada pela Figura 23 no ano de 2012.

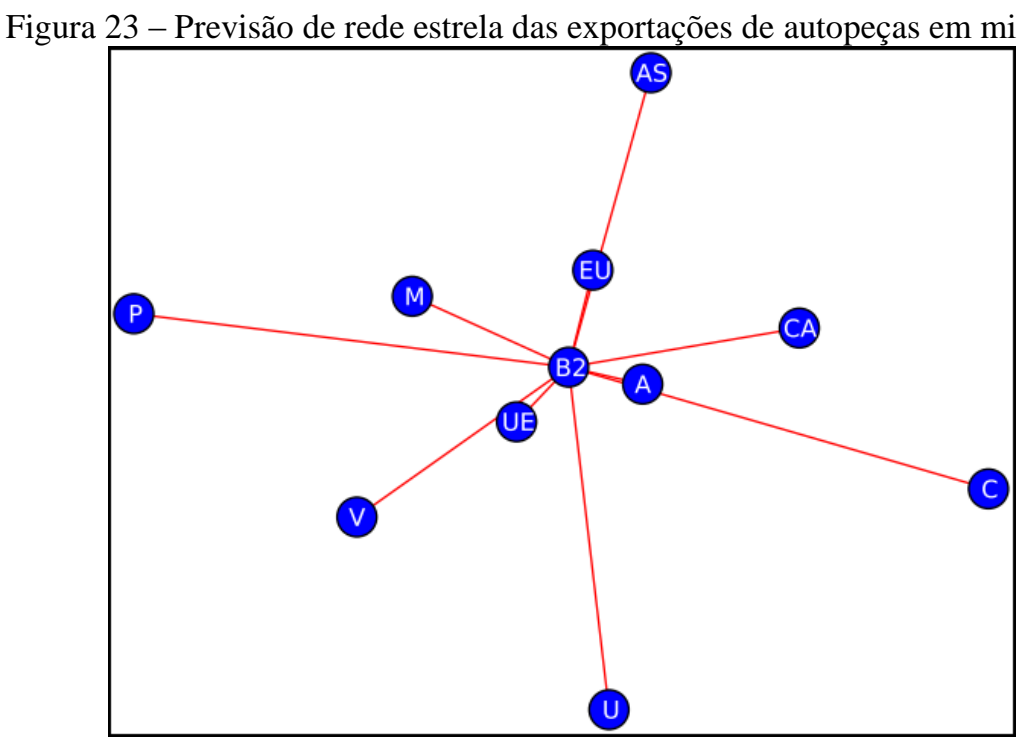

Fonte: Autores (2012)

Na Figura 23 é possível observar a aproximação dos nós Argentina, Estados Unidos e União Europeia em relação ao hub da rede. Comunidade Andina está mais próxima em relação aos demais nós que compõe a rede.

Todos os resultados apresentados, bem como as suas representações, carece de uma análise mais profunda. Pode-se inferir dos dados apresentados algum tendência futura? Como os resultados podem ser utilizados para auxiliar a montadoras de veículos na decisão de se instalar em uma determinada região?

\section{Considerações finais}

As localidades que possuírem uma rede de empresas no setor de autopeças, com alto grau de competência competitiva em relação ao mercado mundial e grande eficiência logística, podem dispor de um diferencial competitivo quanto à decisão sobre a localização de montadoras na região. O investimento de organizações estrangeiras no país revela a potencialidade de lucratividade e importância do setor automotivo para o crescimento industrial.

Com as indústrias de autopeças exercendo a função de sistemistas, este setor torna-se estratégico para a implantação de montadoras em qualquer região do Brasil. Este fator gera a oportunidade de economias regionais serem inseridas podendo inclusive competir no mercado internacional. Uma rede de autopeças desenvolvida pode reduzir custos por parte das montadoras 
que desejam menores gastos para desenvolver fornecedores. Esse conjunto de organizações faz parte da estrutura necessária para manutenção de um complexo automotivo em qualquer região do Brasil. Investimentos no setor de automotivo e de autopeças podem gerar impactos relevantes na economia nacional, sendo o Brasil um país exportador de autopeças, a importância de investimentos nesse setor, torna-se fundamental para o desenvolvimento da área industrial e tecnológica nacional.

Os três principais continentes de destino das exportações de autopeças são a América do Norte, América do Sul e Europa. Existindo a possibilidade das organizações consolidarem seus pedidos em três canais de distribuição concentrados nesses continentes.

A América do Sul impulsionada pela Argentina merece destaque como um parceiro estratégico com privilegiada proximidade territorial, na Américo do Norte os Estados Unidos e a União Europeia no continente europeu são parceiros críticos para o país manter sua vantagem competitiva. Essas nações representam valores consideráveis em milhões de dólares nas exportações brasileiras de autopeças. Existe também a possibilidade de explorar os acordos comerciais existentes na região próxima ao Brasil. Na América do Sul, o MERCOSUL (Mercado Comum do Sul) merece destaque como ambiente para realização de parcerias estratégicas entre os países que compõe esse bloco econômico, pois todos os países destinos das exportações nacionais brasileiras tem alguma relação com o MERCOSUL, que atualmente conta com a Argentina, Brasil, Paraguai, Uruguai e Venezuela como estados membros. A Bolívia, Chile, Peru, Colômbia e Equador são estados associados. O México e a Nova Zelândia são países observadores.

Os experimentos indicaram que as redes que compõe os destinos das exportações nacionais seguem uma lei de potência e são redes livre de escala, um indicador que para o Brasil ser competitivo e maximizar ganhos com exportações de autopeças deve aumentar a quantidade dos países destinos de seus produtos. Uma das consequências do aumento de destinos é a atração de mais consumidores, que antes eram ligados a outros hubs ou países exportadores. O decréscimo dos percentis de Venezuela, Paraguai, África do Sul, Chile e Uruguai, indica que para os próximos anos, as exportações nacionais em milhões de dólares vão se concentrar principalmente na Argentina e depois respectivamente na União Europeia, Estados Unidos e México.

Analisar as exportações nacionais por intermédio das redes complexas e lei de Pareto, pode fornecer aos envolvidos nessa atividade logística, subsídios para elaboração de um planejamento estratégico e indícios de como esse sistema vai se comportar frente às imprevisibilidades do mercado.

\section{Abstract}

This a study aims to analyze the export destination data of national autopart that is a strategic sector for the Brazilian economy, with significant participation in the country's exports. This set of exporting companies form a local productive arrangement that can be analyzed using statistical 
method and the study of complex networks. To perform this analysis, Python computer programming language with some of their libraries, were used. Countries groups have highlighted as targets of national exports in millions of dollars. As presented results, will be possible to develop strategies using the study of complex networks and the Pareto's Law, according to the demands of each distribution channels on the analyzed networks.

Keywords: complex systems; complex networks; local productive arrangement; automotive sector; logistic.

\section{Referências}

ABDI - Agência Brasileira de Desenvolvimento Industrial. Relatório de acompanhamento setorial - Autopeças. Volume I, 2008.

ANFAVEA - Associação Nacional dos Fabricantes de Veículos Automotores. Anuário da Indústria Automobilística Brasileira. São Paulo: ANFAVEA, 2011.

ANGELIS, A. F. Tutorial Redes Complexas. Projeto de Kyatera. Fundação de Amparo à Pesquisa do Estado de São Paulo. USP - Universidade de São Paulo. IFSC - Instituto de Física de São Carlos, 2005. Disponível em:

<http://webensino.unicamp.br/disciplinas/ST464-261483/apoio/4/Tutorial_RedesComplexas.pdf>, Acesso em: 10 de agosto de 2012 .

BOCCALETTI, S.; LATORA, V.; C. MORENO, Y.; CHAVEZ, M.; HWANG, D. U. Complex networks: Structure and dynamics. Physics Reports, n. 424, p. 175-308, feb., 2006.

CARRINGTON, P. J.; SCOTT, J.; WASSERMAN, S. Models and methods in social network analysis. New York: Cambridge University Press, 2005.

cross ref

COSTA, I.; QUEIROZ, S. Autopeças no Brasil: mudanças e competitividade na década de 90. Revista de Administração, v. 35, n. 3, p. 27-37, 2000.

FUSCO, J. P. A. DIAS, R. C. M. Abordagem metodológica para avaliação de relacionamentos de redes de empresas: um exemplo de aplicação na indústria brasileira de autopeças. GEPROS - Gestão da Produção, Operações e Sistemas. n. 1, p. 27-46, jan./mar., 2010.

GARCÍA, M. S. G.; MÉNDEZ, P. N. Los sistemas productivos regionales desde la perspectiva del análisis de redes. Redes Revista Hispana para El Análisis de Redes Sociales. n. 6, p. 79-105, jun./jul., 2004.

GLERIA, I.; MATSUSHITA, R.; SILVA, S. Sistemas complexos, criticalidade e leis de potência. Revista Brasileira de Ensino de Física. v. 26, n. 2, p. 99-108, 2004.

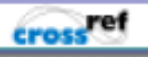

GROSS, J. L.; YELLEN, J. Graph theory and its applications. 2. ed. Boca Raton: Chapman \& Hall, 2006.

HUMPHREY, J.; SALERNO, M. S. Globalisation and assembler-supplier relations: Brazil and India. In: HUMPHREY, J.; LECLER, Y.; SALERNO, M. S. Global strategies and local realities -the auto industry in emerging markets. London: MacMillan, 2000.

cross ref

KOCH, R. Principio 80/20: O segredo de se realizar mais. Rio de Janeiro: Rocco, 2000.

LIMA, C. L.; NASCIMENTO, P. M.; FERREIRA, P.; CAVALCANTE, R.; MACEDO, W. Fornecedores da Ford: Uma Avaliação Preliminar das Oportunidades de Investimento na Bahia. Desenbahia. Estudo Setorial 01/02, set., 2002.

MDIC - MINISTÉRIO DO DESENVOLVIMENTO, INDÚSTRIA E COMÉRCIO EXTERIOR. Brasil: Exportação do Setor Automotivo US\$ Milhões 2005-2011. Brasília, 2011. Disponível em: 〈http://www.comexbrasil.gov.br/> Acesso em: 11 de agosto 2012. 
MURRAY, M. N.; DOWEL, P.; MAYES, D. T. The Location Decision of. Automotive Suppliers in Tennessee and the Southeast. Knoxville: The University of Tennessee, 1999.

NAJBERG, S. PUGA, F. P. Condomínio industrial: o caso do complexo Ford Nordeste. Revista do BNDES. v. 10, n. 19, p. 199-216, jun., 2003. Disponível em: 〈http:www.bndes.gov.br〉 Acesso em: 28 de agosto de 2013.

NEWMAN, M. E. J. Mathematics of networks. In: DURLAUF, S. N.; BLUME, L. E. The New Palgrave Dictionary of Economics. 2. ed. Palgrave Macmillan, 2008.

cross ref

NUSSENZVEIG, H. M. Complexidade e caos. 3. ed. Rio de Janeiro: UFRJ / COPEA, 2008.

PEREIRA, H. B. B.; FREITAS, M. C.; SAMPAIO, R. R. Fluxos de informações e conhecimentos para inovações no arranjo produtivo local de confecções em Salvador, Bahia. DataGramaZero - Revista de Ciência da Informação. v. 8, n. 4, ago., 2007.

ROBLES, L. T. A prestação de serviços de logística integrada na indústria automobilística no Brasil: em busca de alianças logísticas estratégicas. 176 f. Tese (Doutorado em Administração) - Programa de Pós-Graduação em Administração, Faculdade de Economia e Administração, Universidade de São Paulo, São Paulo, 2001.

ROSEMBLOOM, B. Marketing channels: A management view. 8. ed. South-Western: Cengage Learning, 2011.

TORRES, R. L. A indústria automobilística brasileira: uma análise da cadeia de valor. 179 p. Dissertação (Mestrado em Economia) - Programa de Pós-Graduação em Economia, Universidade Federal de Santa Catarina, Florianópolis, 2001.

SFREDO, J. M.; PEREIRA, L. N.; MORAES, P. R. P.; DALMAU, M. Análise de fatores relevantes quanto à localização de empresas: comparativo entre uma indústria e uma prestadora de serviços com base nos pressupostos teóricos. In: ENCONTRO NACIONAL DE ENGENHARIA DE PRODUÇÃO, 26, 2006, Fortaleza. Anais... Fortaleza: ABEPRO, 2006.

TOLEDO, J. C.; SILVA, S. L.; ALLIPRANDINI, D. H.; MARTINS, M. F. FERRARI, F. M. Práticas de gestão no desenvolvimento de produtos em empresas de autopeças. Produção. v. 18, n. 2, p. 405-422, 2008.

\section{cross ref}

VANALLE, R. M.; SALLES, J. A. A. Relação entre montadoras e fornecedores: modelos teóricos e estudos de caso na indústria automobilística brasileira. Gestão \& Produção. v. 18, n. 2, p. 237-250, 2011.

cross ref

WEISS, J. M. G. Estratégias de Localização de Montadoras e Fornecedores de Autopeças no Brasil. In: Encontro Nacional de Engenharia de Produção, 17, 1997, Gramado. Anais... Gramado: ABEPRO, 1997.

\section{Agradecimentos}

Agradecemos pelos apoios que foram concedidos pela Federação das Indústrias do Estado da Bahia (Sistema FIEB), Serviço Nacional de Aprendizagem Industrial (SENAI), Faculdade de Tecnologia do Serviço Nacional de Aprendizagem Industrial - Centro Integrado de Manufatura e Tecnologia (SENAI - CIMATEC) e a Fundação de Amparo à Pesquisa do Estado da Bahia (FAPESB).

\section{Dados dos autores:}

\section{Nome Completo: Bruno Leonardo Santos Menezes}

Titulação: Mestre em Modelagem Computacional e Tecnologia Industrial pela Faculdade de Tecnologia do SENAI - CIMATEC. 
Filiação Institucional: Ex Bolsista de mestrado da Faculdade de Tecnologia do SENAI CIMATEC.

Endereço: Avenida Orlando Gomes, 1845 - Piatã, Salvador - BA, 41650-010.

Telefone para contato: (71) 8805-5159.

e-mail: brunomubarak@gmail.com

\section{Nome Completo: Luciano Pisanu}

Titulação: Mestre em Ciência e Engenharia de Materiais pela Universidade Federal de Campina

Grande.

Filiação Institucional: Professor da Faculdade de Tecnologia do SENAI - CIMATEC.

Endereço: Avenida Orlando Gomes, 1845 - Piatã, Salvador - BA, 41650-010.

Telefone para contato: (71) 8793-0168.

e-mail: lpisanu@fieb.org.br

\section{Nome Completo: Valter de Senna}

Titulação: Pós-doutorado em Estatística pela University of Southampton.

Filiação Institucional: Professor da Faculdade de Tecnologia do SENAI - CIMATEC.

Endereço: Avenida Orlando Gomes, 1845 - Piatã, Salvador - BA, 41650-010.

Telefone para contato: (71) 8788-2741.

e-mail: valter.senna@gmail.com

\section{Nome Completo: Renelson Ribeiro Sampaio}

Titulação: Pós-Doutorado em Economia da Inovação Tecnológica pela Universidade de Wisconsin Madison.

Filiação Institucional: Professor da Faculdade de Tecnologia do SENAI - CIMATEC.

Endereço: Avenida Orlando Gomes, 1845 - Piatã, Salvador - BA, 41650-010.

Telefone para contato: (71) 9125-3082.

e-mail: renelson.sampa@gmail.com

\section{Nome Completo: Márcio Nakayama Miura}

Titulação: Doutor em Administração e Turismo pela Universidade do Vale do Itajaí - UNIVALI Filiação Institucional: Professor da Universidade Estadual do Oeste do Paraná - UNIOESTE

Endereço: Rua Universitária, 2069 - Caixa Postal 711 - Cascavel - PR - 85819-110

Telefone para contato: (45) 9966-5004.

e-mail:adm.parana@gmail.com 


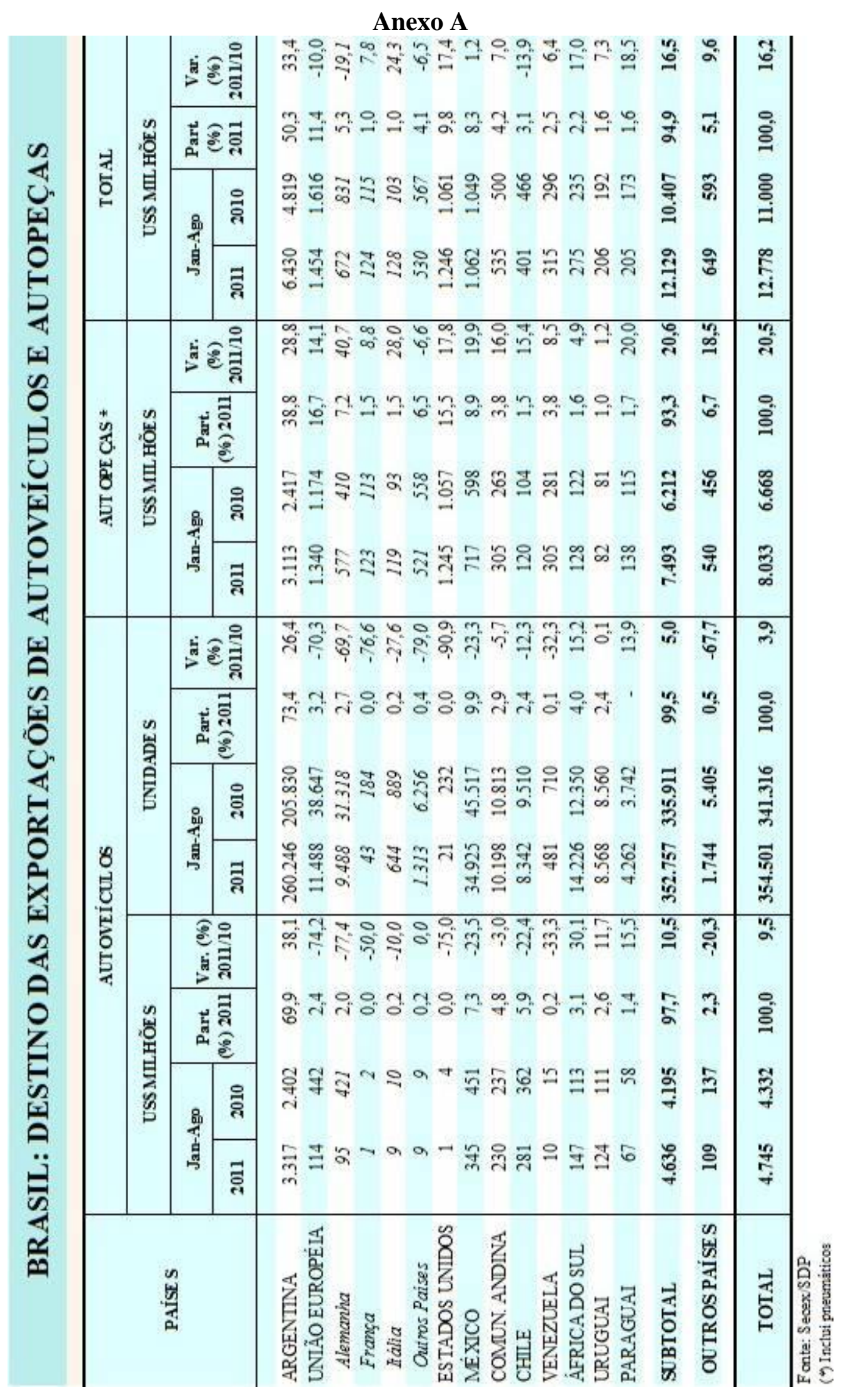




\section{Anexo B}

pc@ubuntu: \$ ipython

Python 2.7.2+ (default, Oct 4 2011, 20:03:08)

Type "copyright", "credits" or "license" for more information.

IPython 0.11 -- An enhanced Interactive Python.

? -> Introduction and overview of IPython's features.

\%quickref -> Quick reference.

help -> Python's own help system.

object? -> Details about 'object', use 'object??' for extra details.

In [1]: import networkx as $\mathrm{nx}$

In [2]: $A=n x . G r a p h()$

In [3]: A.add_edge("B", "A", weight=2417.00)

In [4]: A.add_edge("B", "UE", weight=1174.00)

In [5]: A.add_edge("B", "AL", weight=410.00)

In [6]: A.add_edge("B", "EU", weight=1057.00)

In [7]: A.add_edge("B", "M", weight=598.00)

In [8]: A.add_edge("B", "CA", weight=263.00)

In [9]: A.add_edge("B", "C", weight=104.00)

In [10]: A.add_edge("B", "V", weight=281.00)

In [11]: A.add_edge("B", "AS", weight=122.00)

In [12]: A.add_edge("B", "U", weight=81.00)

In [13]: A.add_edge("B", "P", weight=115.00)

In [14]: import matplotlib.pyplot as plt

In [15]: nx.draw(A, font_color='\#FFFFFF', node_color='\#0000FF', edge_color='\#FF0000')

In [16]: plt.show()

\section{Anexo C}

pc@ubuntu: \$ ipython

Python 2.7.2+ (default, Oct 4 2011, 20:03:08)

Type "copyright", "credits" or "license" for more information.

IPython 0.11 -- An enhanced Interactive Python.

? $\quad$-> Introduction and overview of IPython's features.

\%quickref -> Quick reference.

help $\quad$-> Python's own help system.

object? -> Details about 'object', use 'object??' for extra details.

In [1]: import networkx as $\mathrm{nx}$ 
In [2]: $A=n x \cdot G r a p h()$

In [3]: A.add_edge("B", "A1", weight=2417.00)

In [4]: A.add_edge("A1", "V5", weight=281.00)

In [5]: A.add_edge("V5", "CA6", weight=263.00)

In [6]: A.add_edge("CA6", "P8", weight=115.00)

In [7]: A.add_edge("P8", "C9", weight=104.00)

In [8]: A.add_edge("C9", "U10", weight=81.00)

In [9]: A.add_edge("B", "UE2", weight=1174.00)

In [10]: A.add_edge("B", "AS7", weight=122.00)

In [11]: A.add_edge("B", "EU3", weight=1057.00)

In [12]: A.add_edge("EU3", "M4", weight=598.00)

In [13]: import matplotlib.pyplot as plt

In [14]: nx.draw(A, font_color='\#FFFFFF', node_color='\#0000FF', edge_color='\#FF0000')

In [15]: plt.show()

\section{Anexo D}

pc@ubuntu: \$ ipython

Python 2.7.2+ (default, Oct 4 2011, 20:03:08)

Type "copyright", "credits" or "license" for more information.

IPython 0.11 -- An enhanced Interactive Python.

? $\quad->$ Introduction and overview of IPython's features.

\%quickref -> Quick reference.

help $\quad->$ Python's own help system.

object? -> Details about 'object', use 'object??' for extra details.

In [1]: import networkx as $\mathrm{nx}$

In [2]: $A=n x . G r a p h()$

In [3]: A.add_edge("B", "A", weight= 3113.00)

In [4]: A.add_edge("B", "UE", weight= 1340.00)

In [5]: A.add_edge("B", "AL", weight=410.00)

In [6]: A.add_edge("B", "EU", weight=1245.00)

In [7]: A.add_edge("B", "M", weight=717.00)

In [8]: A.add_edge("B", "CA", weight=305.00)

In [9]: A.add_edge("B", "C", weight= 120.00)

In [10]: A.add_edge("B", "V", weight= 305.00)

In [11]: A.add_edge("B", "AS", weight=122.00)

In [12]: A.add_edge("B", "U", weight= 82.00) 
In [13]: A.add_edge("B", "P", weight= 138.00)

In [14]: import matplotlib.pyplot as plt

In [15]: nx.draw(A, font_color='\#FFFFFF', node_color='\#0000FF', edge_color='\#FF0000') In [16]: plt.show()

\section{Anexo E}

pc@ubuntu: \$ ipython

Python 2.7.2+ (default, Oct 4 2011, 20:03:08)

Type "copyright", "credits" or "license" for more information.

IPython 0.11 -- An enhanced Interactive Python.

? $\quad$-> Introduction and overview of IPython's features.

\%quickref -> Quick reference.

help $\quad->$ Python's own help system.

object? -> Details about 'object', use 'object??' for extra details.

In [1]: import networkx as $\mathrm{nx}$

In [2]: $\mathrm{A}=\mathrm{nx} . \mathrm{Graph}()$

In [3]: A.add_edge("B", "A1", weight=3113.00)

In [4]: A.add_edge("A1", "V5", weight=305.00)

In [5]: A.add_edge("V5", "CA6", weight=305.00)

In [6]: A.add_edge("CA6", "P8", weight=138.00)

In [7]: A.add_edge("P8", "C9", weight=120.00)

In [8]: A.add_edge("C9", "U10", weight=82.00)

In [9]: A.add_edge("B", "UE2", weight=1340.00)

In [10]: A.add_edge("B", "AS7", weight=122.00)

In [11]: A.add_edge("B", "EU3", weight=1245.00)

In [12]: A.add_edge("EU3", "M4", weight=717.00)

In [13]: import matplotlib.pyplot as plt

In [14]: nx.draw(A, font_color='\#FFFFFF', node_color='\#0000FF', edge_color='\#FF0000')

In [15]: plt.show ()

Submetido em: 08/10/2012

Aceito em: 25/08/2013 